\title{
A clinicopathological study and evaluation of significance of argyrophilic staining of nucleolar organizer regions in kidney tumours
}

\author{
T. Elavarasan ${ }^{1}$, M.S. Shruthi ${ }^{2}$, N. Sangeetha ${ }^{3}$ \\ ${ }^{1}$ Dr. T. Elavarasan, Associate Professor, ${ }^{2}$ Dr. M.S. Shruthi, Assistant Professor, ${ }^{3}$ Dr. N. Sangeetha, Assistant Professor, all \\ authores are attached with Department of Pathology, Government Dharmapuri Medical College, Dharmapuri, Tamil Nadu.
}

Corresponding Author: Dr. M.S. Shruthi, Assistant Professor, Department of Pathology, Government Dharmapuri Medical College, Dharmapuri, Tamil Nadu, India. E-mail: froots_dr@yahoo.co.in

\begin{abstract}
A variety of benign and malignant neoplasms arise in the kidneys of adults and children. With the advancement in the recognition of newer variants and wide spectrum of appearances of these tumours especially of nephroblastoma and renal cell carcinoma, the diagnostic accuracy and assessment of critical prognostic indicators for these tumours pose challenges to the surgical pathologists. The present spurt of interest in grading the tumours on morphological and histological criteria and correlating them with AGNOR counts and to the clinical outcome in terms of survival rates is mainly attributable to the recent innovations in surgical and medical oncology. In the present study each of the renal tumour samples were subjected to an argyrophilic staining for the nucleolar organizer region according to the modified colloidal silver technique. In Grade I, II \& III renal carcinoma cases the AgNOR index was $0.875,1.301$, and 1.710 respectively. It has been observed that mean AgNOR indices are directly proportional to grading. i.e., with increased grades the mean AgNOR count also increased and can be used for assessing the clinical outcome and prognosis of the cases. The mean AgNOR scores in epithelial, mesenchymal, blastemal areas for all cases of Wilms' tumour were 4.46, 4.82, and 5.76 respectively. Based on the mean AgNOR score it has been found that blastemal areas have higher score than mesenchymal and epithelial areas. The increased score in blastemal areas can be attributed to increased proliferative activity of the tumour. Prognostication is the most important contribution of the medical scientist to the suffering patient. The AgNOR scoring as a prognostic index helps the clinician in this.
\end{abstract}

Keywords: Renal cell carcinoma, Wilms tumour, AgNOR

\section{Introduction}

A variety of benign and malignant neoplasms arise in the kidneys of adults and children. With the advancement in the recognition of newer variants and wide spectrum of appearances of these tumours especially of nephroblastoma and renal cell carcinoma, the diagnostic accuracy and assessment of critical prognostic indicators for these tumours pose challenges to the surgical pathologists. In several studies, the extent of tumour spread at the time of diagnosis has been correlated with survival. In cases of renal cell carcinoma, various parameters, such as, grade of nuclear pleomorphism, mitotic rate, assessment of cytoplasmic granularity, pseudo capsule thickness and tumour pattern have been investigated with variable success, as possible independent prognostic indicators. [1].

In a similar way, grading, staging and prognostic factors such as D.N.A. ploidy have been employed for the assessment of biological behavior and prognosis of Wilms' tumour [2].

The recent past has seen the emergence of various newer techniques to assess the proliferative capacity of cells. Various proliferation markers like argyrophilic nucleolar organizing regions (AgNORs), Ki-61 and estimation of S phase cells and mitotic cells are used to know the proliferation rate of the nucleus in the cell. A simple, quick, convenient and inexpensive method is the staining and counting of the nucleolar organiser regions. This is based on RNA transcription activity. Silver colloidal solutions of high concentration have been used for this purpose [3]. Due to the high affinity of NORs for silver ions they are called as AgNOR. The present spurt of interest in grading the tumours on morphological and histological criteria and correlating them with AGNOR counts and to the clinical outcome in terms of survival rates is mainly attributable to the recent innovations in surgical and medical oncology. Prognostication is the most important contribution of the medical scientist to the suffering patient. The AgNOR scoring as a prognostic index helps the clinician in this. This

Pathology Update: Tropical Journal of Pathology \& Microbiology Available online at: www.medresearch.in 633 | P a g e 


\section{Original Research Article}

has been an important criterion to assess the malignancy of cells and hence extrapolated to grading of tumors. In the present study AgNOR staining techniques was used on renal tumours and scored it for all the cases of renal cell carcinoma and nephroblastomas. After silver staining, the AgNORs can be identified as black dots throughout the nucleolar area. The number of AgNORs per nucleus suggests it to be a marker of the proliferative activity of the cell. The AgNOR staining technique has an advantage that it can be used in retrospective studies in that cases can be de-stained and re-stained with silver stains. Thus, it can be considered as a valuable tool to assess the proliferative activity of tumours

\section{Aims and Objectives}

1. To study the nature and the types of renal tumours which have been encountered in the Institution during a period of three years.

2. To study the distribution according to age and sex, of the various types of renal tumours.

3. To interpret and assess the histopathological typing and grading of the malignant tumours.

4. To evaluate the role of Argyrophilic staining of nucleolar organizer regions in accurate grading of renal tumours and to compare with other system of grading.

\section{Materials and Methods}

Setting: Department of pathology in a tertiary care centre.

Duration: Two years

Type of the study: Retrospective study

Sampling Method: Specimens were received from the Department of surgery and specimens were fixed in $10 \%$ formalin. After paraffin embedding, $5 \mu$ thin sections were made and stained. Apart from the routine Hematoxylin and eosin stain, special stains like (1) PAS [to demonstrate glycogen], (2) AgNOR staining, were used.

Each of the samples then subjected to an argyrophilic staining for the nucleolar organizer region according to the modified colloidal silver technique.

Inclusion criteria: All the nephrectomy specimes with renal tumours were included in the study.

Exclusion criteria: All the non tumourous nephrectomy specimens were excluded from the study

AgNOR Score: The stained slides were viewed under oil immersion and intra nuclear silver dots are hand counted making use of light microscope. After counting atleast 100 cells, AgNOR score was calculated, ie. Mean number of AgNOR dots per nucleus. The count was repeated by another person to minimize observer error.

AgNOR Index: In renal cell carcinoma after staining the sections were examined under oil immersion, careful focusing was employed to resolve individual NORs in clusters as well as satellite NORs scattered throughout the nucleus. A total of 100 nuclei, randomly chosen from both tumour part and non-neoplastic proximal tubules in each section, were evaluated and the NOR index for each section was obtained from the following formula:

Mean NOR count in tumour nuclei

$$
\text { NOR index = - Mean NOR count in the nuclei of proximal tubules }
$$

In Wilms' tumour the mean AgNOR score was derived separately for blastemal, mesenchymal and epithelial areas for each case. Then the mean AgNOR score for all cases in blastemal, mesenchymal and epithelial areas were calculated separately and evaluated.

\section{Results}

The types of malignant tumours are given in Table 1. Wilms' tumour is the most common malignant tumour, followed closely by renal cell carcinoma, Wilms' tumour constitutes $46.15 \%$ of all renal neoplasms whereas renal cell carcinoma Constitutes $41.62 \%$. The others are comparatively less common constituting together $12.80 \%$ only.

Distribution of malignant tumours according to sex is given in Table 2. In both Wilms' tumour and renal cell carcinoma males are more commonly affected than females. In Wilms' tumour out of 18 cases, 12 cases occurred in males [66.6\%] and 6 in females [33.3\%]. 
In renal cell carcinoma out of 16 cases, 11 cases occurred in males [68.75\%] and 5 cases occurred in females [31.25\%].

Patients with Wilms tumour showing age distribution given in Table 3. Age ranged from 8 months to 25 years with most of the cases occurring between 1 to 2 years. There was one case below one year and two cases above 9 year.

Table-1: Type of malignant neoplasms.

\begin{tabular}{|l|c|c|}
\hline \multirow{2}{*}{ Type } & \multicolumn{2}{|c|}{ Present Study } \\
\cline { 2 - 3 } & No. & Percentage \\
\hline 1. Wilms' tumour & 18 & 46.15 \\
\hline 2. Renal cell carcinoma & 16 & 41.02 \\
\hline 3. Transitional cell carcinoma & 2 & 5.12 \\
\hline 4. Clear cell sarcoma & 2 & 5.12 \\
\hline 5. Secondaries & 1 & 2.56 \\
\hline
\end{tabular}

Table-2: Distributions of malignant tumours according to sex.

\begin{tabular}{|c|c|c|c|c|c|}
\hline & \multicolumn{2}{|c|}{ Males } & \multicolumn{2}{c|}{ Females } & \multirow{2}{*}{ Male:Female } \\
\cline { 2 - 5 } & No. & Percentage & No. & Percentage & \\
\hline Wilms' tumour & 12 & 66.6 & 6 & 33.3 & $2: 1$ \\
\hline Renal cell carcinoma & 11 & 68.75 & 5 & 31.25 & $2.2: 1$ \\
\hline
\end{tabular}

Table-3: Age distribution of patients with Wilms' tumour.

\begin{tabular}{|c|c|c|c|c|}
\hline Age & Males & Females & Total No. & Percentage \\
\hline Below 1 year & 1 & - & 1 & 5.55 \\
\hline 1 to 2 years & 4 & 1 & 5 & 27.71 \\
\hline 2 to 3 years & 2 & - & 2 & 11.11 \\
\hline 3 to 4 years & - & 1 & 1 & 5.55 \\
\hline 4 to 5 years & 1 & 2 & 3 & 16.66 \\
\hline 5 to 6 years & 1 & - & 1 & 5.55 \\
\hline 6 to 7 years & 1 & 1 & 2 & 11.11 \\
\hline 8 to 9 years & - & 1 & 1 & 5.55 \\
\hline Above 9 years & 2 & - & 2 & 11.11 \\
\hline
\end{tabular}

Table-4: Age distribution of patients with renal cell carcinoma.

\begin{tabular}{|c|c|c|c|c|}
\hline Age & Males & Females & Total No. & Percentage \\
\hline $21-30$ years & - & 1 & 1 & 6.25 \\
\hline $31-40$ years & 1 & 2 & 3 & 18.75 \\
\hline $41-50$ years & 2 & - & 2 & 12.50 \\
\hline $51-60$ years & 4 & 2 & 6 & 33.33 \\
\hline $61-70$ years & 4 & - & 4 & 25.00 \\
\hline
\end{tabular}

Table-5: Histological grading of renal cell carcinoma.

\begin{tabular}{|c|c|c|}
\hline & No. & Percentage \\
\hline Grade I & 1 & 6.25 \\
\hline Grade II & 10 & 62.50 \\
\hline
\end{tabular}

Pathology Update: Tropical Journal of Pathology \& Microbiology Available online at: www.medresearch.in 635 | P a g e 
Original Research Article

\begin{tabular}{|c|c|c|}
\hline Grade III & 5 & 31.25 \\
\hline Grade IV & - & - \\
\hline
\end{tabular}

Table-6: Related pathological changes in adjacent tissues in renal cell carcinoma.

\begin{tabular}{|l|c|c|}
\hline \multirow{2}{*}{} & \multicolumn{2}{|c|}{ Present Study } \\
\cline { 2 - 3 } & No. & Percentage \\
\hline 1. Interstitial nephritis & 15 & 93.75 \\
\hline 2. Hydronephrotic changes & 4 & 25.0 \\
\hline 3. Vascular changes & 6 & 37.5 \\
\hline 4. Renal adenomas & - & - \\
\hline
\end{tabular}

Table-7: Mean nor indices of renal cell carcinoma.

\begin{tabular}{|c|c|c|c|}
\hline NOR Index & Range & Mean & SD \\
\hline Grade I & - & 0.875 & - \\
\hline Grade II & $1.125-1.444$ & 1.301 & 0.24 \\
\hline Grade III & $1.555-1.888$ & 1.710 & 0.25 \\
\hline All Cases & $0.875-1.888$ & 1.402 & 0.52 \\
\hline
\end{tabular}

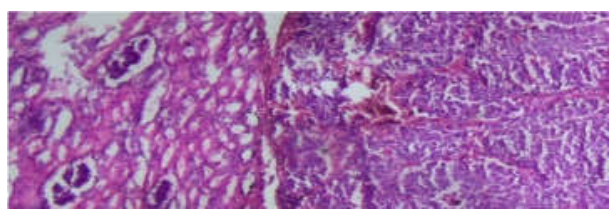

Figure-1: Microscopic appearance of neuroblastoma infiltrating the renal parenchyma.

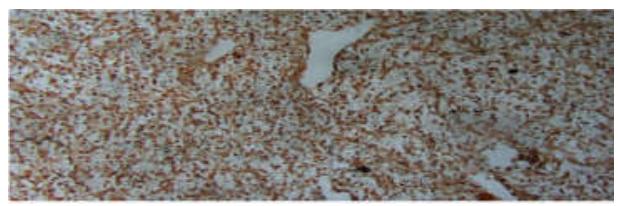

Figure-2: Low power microscopic picture of Grade I renal cell carcinoma stained with AgNOR stain.

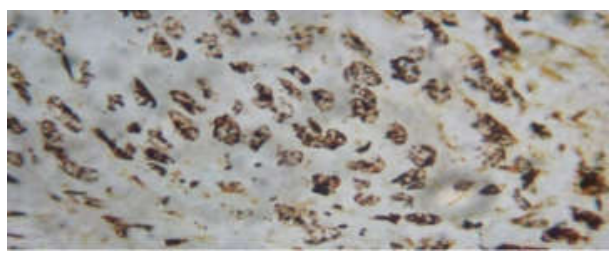

Figure-3: Pattern of AgNOR staining in Grade III renal cell carcinoma showing multiple AgNOR dots inside the nucleus of tumour cell.

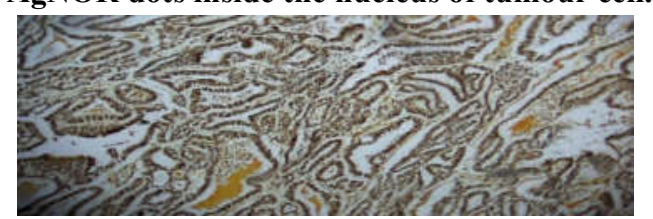

Figure-4: Pattern of AgNOR staining in monomorphic Wilms' tumour.

Age distribution of patients with renal cell carcinoma is given in Table 4. The age ranged between 20 to 70 years with median age in the fifth decade which showed the maximum occurrence of $33.33 \%$ of the cases seen.

Histological grading of the tumours was done based on Fuhrman's nuclear grade. The present study shows two thirds of the cases come under grade II constituting $62.5 \%$ as shown in Table 5. Related pathological changes in adjacent tissues in renal cell carcinoma was represented through Table 6.

Pathology Update: Tropical Journal of Pathology \& Microbiology Available online at: www.medresearch.in 636 | P a g e 
Original Research Article

Table 7 shows the mean AgNOR indices of renal cell carcinoma. All cases of Renal cell carcinoma were successfully stained by Silver - Colloid method. The NOR indices were calculated by the formula. The average of the NOR index of all cases was 1:402.

Mean NOR counts in tumour nuclei
Mean NOR counts in the nuclei of proximal
Renal tubules

It has been noted that mean AgNOR indices are directly proportional to grading. i.e., when the grading of the tumour is increased the mean AgNOR count is also increased. Most of the cases were Grade II lesions with the mean AgNOR count of 1:301. One case of Grade I lesions has been found in which the mean AgNOR was 0.875, whereas the mean AgNOR in Grade III cases was 1:710

Like renal cell carcinoma, AgNOR staining was done in all cases of Wilms tumour. It has been noted that mean AgNOR score in epithelial areas for all cases were 4.46. In mesenchymal areas the score was 4.82, and in blastemal areas the score was 5.76 .

In clear cell sarcoma the mean AgNOR Score was 7.56, whereas urothelial carcinoma arising from renal pelvis showed a score of 5.16 .

\section{Discussion}

The tumours of the kidney are a complex group; their histogenesis is controversial, their structure variable, and their behavior capricious [4]. Though both benign and malignant tumours occur in the kidney, benign tumours are often incidental findings at autopsy and rarely have clinical significance [5]. The malignant tumours on the other hand, cause considerable morbidity and mortality and are of great clinical significance [6].

Renal cell carcinoma accounts for $85 \%$ of all renal malignancies in the adult and older age group [7]. The neoplasm originates from the epithelium of proximal convoluted tubules. In the present study, the age incidence denotes the maximum occurrence in the fifth decade and the male to female ratio indicates the higher incidence in males. This is in concordance with the study earlier [8].

The present study observed Wilm's tumor as the most common neoplasm. This is in concordance with the study conducted earlier [9]. However, other studies showed Renal cell carcinoma as the most common neoplasm [2]. The present study showed that like in Renal cell carcinoma, Wilms' tumour were also seen more commonly in males than females constituting a ratio of $2: 1$. Most of the cases in Wilms tumour occurred between the age of 1 to 2 years constituting $27.71 \%$ and two cases occurred above 9 years. This is in concordance with the study done earlier [9].

Clear cell sarcoma (Bone Metastasising tumour of childhood or undifferentiated sarcoma) of kidney is a highly malignant tumour with bone metastasis in about $60 \%$ of cases. In the present study, two cases $(5.12 \%)$ of between 24 and 36 months of age was observed. Both were male patients. This was in concordance with the study done by Argani P et al [10]. In the present study, two cases of transitional cell carcinoma (5.12\%) arising from renal pelvis which are grade II neoplasms and this was in accordance with the earlier study [11].

Histopathological grading of the tumours in the present study showed that about two third of the cases come under grade II and this was done based on the nuclear characteristics of the cells as done by the study done earlier [12]. Many studies have attempted to identify clinical and/or histological parameter that may assist in assessing outcome in patients with Renal Cell Carcinoma. Tumour grade has been shown in several reported series to provide survival data that are independent of stage. Those tumour exhibiting low grade of nuclear pleomorphism were associated with long-term survival while the converse applied to high-grade malignancies [13].

Grading of renal cell carcinoma is complicated by the lack of universally accepted grading system, and it has been suggested that grading is too subjective and is too lacking in reproducibility to be of clinical value [14].

In the present study, the renal parenchyma adjacent to the neoplasm showed histological evidence of pathological changes such as interstitial nephritis, hydronephrotic changes and vascular changes. Similar observations were also made in earlier studies in which also interstitial nephritis was the most common change [8]. 


\section{Original Research Article}

Nucleolar organizer regions are intranuclear structures that appear to be various nonhistone proteins associated with loops of DNA. They may become more numerous when cell activity, especially protein production and / or ploidy is increased. Therefore, they are detected on light microscopy by silver colloid staining. This method permits retrospective analysis of archival materials. Therefore, it is possible that many tumours would be detected in the study. Various studies have indicated that the number of NORs identifiable by the silver colloid method is related to cellular proliferation in malignant tissues [3].

In the present study it was noted that AgNOR index for all cases was 1.402. In Grade I, II \& III cases the AgNOR index was $0.875,1.301$, and 1.710 respectively. It has been observed that mean AgNOR indices are directly proportional to grading. i.e., with increased grades the mean AgNOR count also increased and can be used for assessing the clinical outcome and prognosis of the cases. The findings from the present were similar to the findings of the study done earlier [14]. However, the mean AgNOR indices in the present study for all cases were quite higher in contrast to the study done earlier. The high mean AgNOR indices in the present study observed can be attributed to Type 2 method of counting AgNOR dots in the nucleus of tumour cells. The AgNOR score will be higher in Type 2 method of counting than Type 1 method of counting.

It has been found that Crockers type 2 counting method is more useful in grading the tumours than type 1 method. The AgNOR values in the cells of renal cell carcinoma were significantly higher than those of non-neoplastic proximal tubules. And the numbers increased with the progress of the grades of renal cell carcinoma [15].

Like renal cell carcinoma all cases of Wilms' tumour are stained with AgNOR staining, it has been noted that mean AgNOR scores in epithelial, mesenchymal, blastemal areas for all cases were 4.46, 4.82, and 5.76 respectively. Based on the mean AgNOR score it has been found that blastemal areas have higher score than mesenchymal and epithelial areas. The increased score in blastemal areas can be attributed to increased proliferative activity of the tumour [16].

The few limitations of the study are resolution of the individual AgNOR within relatively small nucleolus, affinity of the nucleolus for silver stain which obscures the dots in case of intense staining and variable degree of overlap between high and low grade tumours. However, AgNOR staining technique has many advantages like

cost effectiveness, easy to use, its simplicity and good correlation with other proliferation markers.

\section{Conclusion}

Prognostication is the most important contribution of the medical scientist to the suffering patient. Apart from enabling the clinician to plan the proper utilization of the expensive and often limited resources at his disposal, such a capacity adds to a humanistic contribution. The AgNOR stain is of importance as it indicates the tumour aggressiveness. It acts as a supportive tool to the routinely performed $\mathrm{H} \& \mathrm{E}$ staining and the AgNOR scoring as a prognostic index may well prove to be a trend setter in replacing the pessimistic nihilism with scientific optimism.

\section{What the study adds to the existing knowledge?}

The study shows the importance of AgNOR in prognostication of renal tumors which further substantiates the importance of a relatively inexpensive method like AgNOR staining in tumour prognostication and thus aids in further management of the patient.

\section{Author's contribution}

All Authors had equally contributed in every part of research like manuscript writing, data collection and statistical analysis.

\section{References}

1. Volpe A, Patard JJ. Prognostic factors in renal cell carcinoma. World J Urol. 2010;28(3):319-327. doi: 10.1007/s00345-010-0540-8. Epub 2010 Apr 3.

2. Abou-Rebyeh H, Borgmann V, Nagel R, Al-Abadi H. DNA ploidy is a valuable predictor for prognosis of patients with resected renal cell carcinoma. Cancer. 2001;92(9):2280-2285. doi: https://doi.org/10.1002/10970142(20011101)92:9<2280::AIDCNCR1574>3.0.CO;2-2

3. Behnam E, Hessam R, Farzaneh R,Monir M, Khiavi, Asgharv E. Diagnostic value of silver nitrate staining for nucleolar organizer regions in selected head and neck tumor. J Cancer Res Ther. 2006;2(3):129-133. doi:10.4103/0973-1482.27588

4. Lucke B, Schlumberger, HG. Tumours of kidney, renal pelvis and ureter. Atlas of Tumor Pathology, Sect 8, Fasc 30. Armed Forces Institute of Pathology, Washington. 
5. Robbins SL., Cotran RS, Kumar V. Pathological basis of disease. III ${ }^{\text {ed }}$, Philadelphia Saunders. 1984;1053-8.

6. Rubin E, Farber JL. Environmental diseases of the digestive system. Med Clin North Am. 1990;74(2):413424. doi:10.1016/s0025-7125(16)30570-3

7. Shalini A, Jatinder K, Manoj J, Rakesh K, Anil M. Renal cell carcinoma in India demonstrates early age onset and a late stage of presentation. Indian J Med Res. 2014;140(5):624-629.

8. Usha, Singh RG, Gupta SN, Gupta RM, Gupta IM, Singh PB. Histological changes in kidney surrounding the renal cell carcinoma. Indian $\mathrm{J}$ Pathol Microbiol. 1987;30(4):369-373.

9. Varsha H, Arun D. A Study of surgical profile of patients with Wilms's tumor. Int Surg J. 2016;3(1):314317. doi:10.18203/2349-2902.

10. Pedram A, Elizabeth JP, Norman EB, Neil GB, Daniel MG, Gulio J.Clear Cell Sarcoma of the Kidney: A Review of 351 Cases From the National Wilms Tumor Study Group Pathology Center. Am J Surg Pathol.2000;24(1):4-18.

11. Reitelman C, Sawczuk IS, Olsson CA, Puchner PJ, Benson MC. Prognostic variables in patients with transitional cell carcinoma of the renal pelvis and

\section{Original Research Article}

proximal ureter. J Urol. 1987;138(5):1144-1145. doi:10.1016/s0022-5347(17)43528-2

12. Fuhrman SA, Lasky LC, Limas C. Prognostic significance of morphologic parameters in renal cell carcinoma. Am J Surg Pathol. 1982;6(7):655-663.

13. Delahunt B, Nacey JN. Renal cell carcinoma II. Histological indicators of prognosis. Pathology. 1987;19(3):258-263. doi: 10.3109/00313028709066560.

14. Shimazui T, Tomobe M, Hattori K, Uchida K, Akaza $\mathrm{H}$, Koiso. Prognostic significance of nucleolar organiser regions in renal cell Carcinomas. $J$ Urol. 1995;154(4);1522-1526. doi:10.1016/S00225347(01)66921-0

15. Yamamoto N. [Studies of argyrophilic nuclear organizer region proteins in renal cell carcinoma. Its significance as a marker of proliferative activity]. Nihon Hinyokika Gakkai Zasshi. 1993;84(8):1441-1449. doi:10.5980/jpnjurol1989. 84.1441

16. Berrebi D, Leclerc J, Schleiermacher G, Zaccaria I, Boccon-Gibod L, Fabre M, et al. High cyclin E staining index in blastemal, stromal or epithelial cells is correlated with tumor aggressiveness in patients with nephroblastoma. PLoS One. 2008;3(5):e2216. doi: 10.1371/journal.pone.0002216.

\section{How to cite this article?}

T. Elavarasan, Shruthi, N. Sangeetha. A clinicopathological study and evaluation of significance of argyrophilic staining of nucleolar organizer regions in kidney tumours. Trop J Path Micro 2019;5(9):633-639.doi:10.17511/jopm.2019.i09.04. 